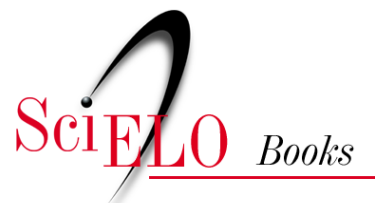

\title{
3. Nervos e nervosas na biomedicina
}

\author{
Maria Lucia da Silveira
}

\section{SciELO Books / SciELO Livros / SciELO Libros}

SILVEIRA, M. L. Nervos e nervosas na biomedicina. In: O nervo cala, o nervo fala: a linguagem da doença [online]. Rio de Janeiro: Editora FIOCRUZ, 2000. Antropologia e saúde collection, pp. 61-82. ISBN: 978-85-7541-609-9. Available from: doi: 10.7476/9788575416099.004. Also available in ePUB from: http://books.scielo.org/id/k4vp7/epub/silveira-9788575416099.epub.

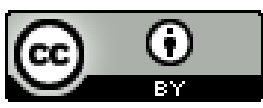

All the contents of this work, except where otherwise noted, is licensed under a Creative Commons Attribution $\underline{4.0 \text { International license. }}$

Todo o conteúdo deste trabalho, exceto quando houver ressalva, é publicado sob a licença Creative Commons Atribição 4.0. 


\title{
3
}

\section{Nervos e Nervosas na Biomedicina'}

\section{Da Sufocação a0s Nervos: a construção da representação MÉDICA DE UM SOFRIMENTO}

\begin{abstract}
A construção refere-se ao processo material lento e prático pelo qual as inscrições se superpõem e as descrições são mantidas ou refutadas.

Latour \& Woolgar
\end{abstract}

Embora o fenômeno ora estudado sob a denominação de nervos, na interpretação que lhe dou, não tenha a mesma explicação etiológica e nem o mesmo significado social da histeria, do ponto de vista biomédico e histórico coincide com o seu quadro. Como conseqüência disso, conceitos e interpretações na medicina ocidental tiveram uma tal influência que repercutem ainda na atenção aos sofredores de nervos, permeandoa de preconceitos. Cabe, por isso, relembrar sua trajetória desde os tempos hipocráticos, apontando aqui momentos exemplares que contribuíram decisivamente para a formulação presente da representação da histeria e de nervos. ${ }^{2}$

Semanticamente, o termo histeria remete à ligação com o útero (do grego hystera) e à idéia, que remonta à Antigüidade (cerca de 2000 a. C.), do útero como um organismo vivo análogo a um animal, dotado de certa autonomia e de condições de deslocamento pelo corpo.

No século IV a. C., Hipócrates referia-se freqüentemente à mobilidade do útero pelo corpo; à doença provocada por essa migração, ele chamava de sufocação da matriz. Segundo Trillat (1991a), Hipócrates utilizava apenas essa expressão, e teria sido Litré quem, no século XIX, a substituiu pelo termo histeria.

Ainda hoje em dia, a descrição hipocrática se presta para descrever com muita precisão alguns dos quadros relatados por sofredoras de nervos, como se pode observar comparando o seu relato com o de uma paciente:

Eis como isso ocorre: a mulher tendo os vasos mais vazios que de costume e estando mais cansada, a matriz ressecada pela fadiga se desloca, visto que ela está vazia e leve; a vacuidade do ventre faz com que haja lugar para que ela se desloque. 
Estando deslocada, ela se joga sobre o fígado, adere a ele e se dirige para os hipocôndrios. Com efeito, ela corre e vai para o alto em direção ao fluido, visto que ela foi demasiado ressecada pela fadiga. Ora, o fígado está cheio de fluido. Quando ela se joga sobre o fígado, ela causa uma sufocação súbita, interceptando a via respiratória que está no ventre. Por vezes, ao mesmo tempo que a matriz começa a se jogar sobre o fígado, desce fleuma da cabeça para os hipocôndrios, dado que a mulher está sufocada; e por vezes, com essa descida de fleuma (ou pituíta, humor frio), a matriz deixa o fígado, retorna a seu lugar e a sufocação cessa... Quando a matriz está no fígado e nos hipocôndrios e produz a sufocação, o branco dos olhos revira, a mulher fica fria e mesmo, por vezes, lívida. Ela range os dentes, a saliva flui à boca e ela se assemelha aos epiléticos. Se a matriz fica muito tempo fixada ao fígado e nos hipocôndrios, a mulher sucumbe, asfixiada. (...) Ela experimenta esses acidentes subitamente, em plena saúde. (Hipócrates apud Trillat, 1991b:20)

Eu sinto que a crise está começando porque me vem uma coisa, parece uma dor, não sei explicar bem... aqui debaixo, parece que uma coisa aqui, não sei se éo útero ou o que é, uma coisa aqui se retorce e parece que sobe, parece um bicho se mexendo lá por dentro, vem assim pelo lado esquerdo, daí passa para o lado de cá [o direito, e aponta a região anatômica que corresponde ao fígado], quando chega aqui essa dor provoca uma agonia, parece que vou ficando sufocada, prende a respiração, parece que não tenho mais ar, aí sobe mais um pouco e me ataca o coração, ai ele bate descompassado, às vezes parece que vai parar, às vezes parece que vai atropelar de tão depressa que bate, acho que vou morrer..., parece que fecha minha garganta, não consigo falar, às vezes só dou uns guinchos que nem animal! Aí a vista escurece ou então me dá um branco na vista que não vejo mais nada. Nessa hora, se ainda não caí, eu caio, não vejo mais nada, perco o conhecimento, depois eles é que me contam que eu fui ficando esquisita e caí. Tem dia que a crise dá e eu escuto tudo, só não posso falar, não consigo dizer o que tá acontecendo comigo, às vezes eu me bato que nem quem tem ataque, me babo, eles dizem que até os olhos eu retorço quando a crise é feia mesmo. Isso dá assim, sem mais nada, não precisa acontecer nada antes, o ataque vem por ele mesmo e, assim como veio, vai embora, deixa uma zonzura, uma fraqueza ruim, uma tristeza funda na gente. (Paciente)

Essa compreensão persiste por séculos com pequenas variações conceituais, que incluem a redução da alma animal a uma comparação - "de modo que a matriz é inteiramente para a mulher como um animal dentro de um animal" - feita por Aretée de Cappadoce, médico radicado em Roma no primeiro século (apud Trillat, 1991c).

Ao final do primeiro século de nossa era, Soranus de Éfeso, o Príncipe dos Metódicos, propôs que a matriz seria fixada por membranas delgadas aos órgãos que a rodeiam. Até então, acreditava-se que elas só poderiam desenvolver movimentos muito pequenos. Soranus entendia que o útero, justamente pela delicadeza dessas membranas de fixação, poderia movimentar-se amplamente: a sensibilidade ao toque o faria passível de se contrair com os adstringentes e relaxar-se com os emolientes.

Um século adiante, Galeno estabeleceu uma teoria sexual ou seminal para a histeria, atribuindo à mulher a emissão de uma semente análoga ao esperma masculino, e entendeu que seus órgãos genitais seriam semelhantes aos masculinos, só que situ- 
ados internamente. A doença seria provocada por uma retenção da semente feminina. Pela teoria galênica, seriam mais suscetíveis à histeria as mulheres que estivessem mantendo relações sexuais regulares e delas fossem bruscamente privadas.

Galeno desfez a confusão que persistia desde Hipócrates, com o uso do termo nervos para designar indiscriminadamente tendões, nervos propriamente ditos, músculos e ligamentos; a ele deve-se o reconhecimento da interligação entre os nervos e o cérebro. Ele também promoveu a clivagem entre ciência e fé, ao mesmo tempo em que introduziu uma distinção entre causas naturais e não naturais - coisas contrárias à natureza da alma, que provocariam afecções e não dependiam de causas naturais.

$\mathrm{O}$ adjetivo nervoso aparece no século XIII, com o sentido que lhe era atribuído na língua latina, ligado ao vigor derivado da fibra, nervus, com o mesmo sentido que tinha o neuron grego, mais tarde nervo, que não se reduz apenas a uma designação anatômica, mas, destacando-se do contexto morfológico, adquire com freqüência um tom pejorativo, a meio caminho entre a patologia e a dor (Israël, 1995b).

$\mathrm{Na}$ Renascença, as forças antinaturais propostas por Galeno no século II foram tidas como emanadas do diabo. A histeria e a melancolia passaram a ser vistas como resultante da ação de tais forças. Nessa linha, Paracelso, Cornelius, Agrippa e seu discípulo Jean Wier foram defensores das bruxas, mulheres então caçadas pela Inquisição, acusadas de pactuar voluntariamente com o diabo. Mais tarde, as bruxas foram identificadas às histéricas convulsivas, e o debate médico-teológico, que pretendia distinguir possessões demoníacas, simulação e doenças como a histeria e a epilepsia, se prolongou por todo o período em que vigorou a Inquisição.

Ao fim do século XVII, surgiram duas teorias para explicar a histeria: uma teoria vaporosa, seguida por ginecologistas e parteiros, baseada nas, então, recentes descobertas da química e da física dos gases; e a outra, seguida por neurologistas que se apoiavam em teorias neurológicas modernas. Ambas lançavam mão dos nervos como estrutura anatômica capaz de fazer fluir os seus vapores, porém continuavam postulando a presença de espíritos animais como origem de transtornos. Em 1689, Lange, em seu Tratado dos Vapores, retoma a histeria como doença sexual cuja sede é o útero.

Em 1758, Raulin atribui a sintomatologia histérica a uma muito vaga irregularidade no sistema nervoso, desenvolvendo uma teoria das paixões, às quais a mulher estaria particularmente exposta por ter uma natureza mais sensível. No mesmo século, Sydenhan, chamado de Hipócrates da Inglaterra, postulava a existência de uma relação monista entre mente e corpo, na qual a desordem dos espíritos animais acarretaria uma viciação dos humores. Tanto quanto no corpo, os humores, o sangue, as fermentações estariam implicados no desenvolvimento das paixões. Foi nesse tempo que o útero deixou de ser tido como a sede da histeria e o cérebro assumiu tal posição, embora a teoria uterina mantivesse defensores até o século XIX, e talvez ainda hoje os mantenha. 
Ainda no século XVIII, o escocês Whytt adotou a compreensão de doença dos nervos, atribuindo a histeria e a hipocondria a uma constituição fraca ou contranatural dos nervos. Ele interessou-se pelo efeito das emoções sobre o sistema nervoso, o que hoje é chamado de psicofisiologia. Seu contemporâneo, William Cullen, inventor da palavra neurose, cuja função era afirmar a preponderância da neurologia, entendia a histeria como uma neurose (no sentido por ele proposto de doença dos nervos), porém ainda a ligava ao útero e aos ovários.

É preciso lembrar que, por essa época, as áreas de influência relacionadas a gênero começavam a diferenciar-se mais: tornava-se norma que as funções organizadas, públicas, econômicas e políticas fossem exercidas idealmente pelo homem, ao passo que o poder da mulher colocava-se crescentemente no âmbito doméstico. As relações sociais estabelecidas sobre tais bases revelavam, primariamente, relações de poder fundadas nas relações de gênero. Nesse contexto, ganhou força a ideologia da grande vulnerabilidade física e emocional da mulher, característica tida como própria da natureza feminina e necessária para gerar e dar à luz os seus filhos. Convém assinalar que as diferenças entre os gêneros aplicavam-se apenas às camadas socialmente mais favorecidas; entre os pobres, vigorava ainda o trabalho escravo ou escravizado. Assim, papéis ligados a gênero, assim como diagnósticos médicos, não eram similares ou operativos para os trabalhadores, minorias étnicas e raciais e para os pobres.

Ao mesmo tempo, ocorria na Europa o período inglês da história da histeria, marcado pela influência das descobertas no campo da neurologia e pela mentalidade puritana da Inglaterra: era necessário abandonar toda referência ao exercício da sexualidade. A idéia de que histeria tem origem uterina era totalmente inadequada, por evocar constantemente a associação entre o útero e a função sexual.

Com o advento do romantismo do século XIX, a discussão sobre a histeria mantém-se como questão predominantemente feminina. Mas é lançada no bojo mais amplo da natureza da mulher e do papel da sexualidade nas diversas etapas psicossociais de sua vida - puberdade, casamento, viuvez.

Embora o imaginário romântico, que colocava a mulher num pedestal, afetasse os médicos que tratavam da questão, o útero voltava ao centro da discussão sobre a nosologia feminina. Foi por esse tempo que os fisiologistas descobriram a ovulação, evidenciando o papel gerador e ativo da mulher na reprodução.

Se não emancipou a mulher, o romantismo ao menos reconheceu nela um ser sexuado, completamente diferente do homem, o que motivou os médicos a procurar em o que diferenciava a sua natureza da dos homens, e permitiu que se retomasse, mais uma vez, a reunião da histeria e da hipocondria como uma mesma doença, tal como propusera Sydenham.

Em 1879, o médico norte-americano Beard descreveu a neurastenia, um quadro bastante próximo da melancolia e da hipocondria. Chegou-se, assim, ao final do século XIX, à necessidade de diferenciar a histeria da neurastenia, vista por Beard como um estado de fadiga física e psicológica, acompanhada de múltiplas indisposições de expressão corporal. 
Começava-se a abandonar os fatores até então tomados como responsáveis por tais quadros, como hereditariedade, clima, educação, paixões, emoções, tóxicos etc. A etiologia proposta por Beard substituía-os por fatores sociais: o desenvolvimento da sociedade industrial como causa de um esgotamento energético que estaria na base das neuroses.

Com a aproximação do século XX, com suas incertezas e mudanças sociais e políticas, a histeria passou também a ser entendida num contexto sociológico. Isso ocorria à medida que avançavam as reivindicações femininas pela igualdade de direitos, emancipação e afirmação da própria identidade.

Em 1901, Babinski propôs substituir o termo histeria, caduco para ele, por pitiatismo, referindo-se a uma classe de fenômenos mórbidos passíveis de cura pela persuasão.

Por essa época, propalou-se um desaparecimento da histeria, refutado por Janet com o argumento de que, na verdade, a mesma persistia, mas estava sendo pesquisada adequadamente na clínica.

As bases pragmáticas dos tratamentos adotados até esse momento, que conferiam à histeria um caráter superficial, foram rompidas pela proposta psicanalítica de Sigmund Freud. Em 1895, juntamente com Breuer, ele publicou os Estudos Sobre a Histeria, marco fundador da psicanálise e da revolução por ela desencadeada.

Freud desenvolveu a teoria dos níveis de consciência e propôs que traumas e repressões severas, especialmente aqueles ligados à sexualidade, estariam na origem do fenômeno histérico.

A grande importância conferida pela psicanálise à sexualidade parece ter influenciado ainda mais a prática médica desde então. Talvez porque a medicina tenha encontrado na teoria freudiana uma forma de perpetuar a sua idéia de correlação da histeria com o sexo e, por conseqüência, a noção médica ligada ao diagnóstico popular de nervos, envolvendo nessa implicação quase que exclusivamente o sexo feminino. A prática médica reduziu esse tipo de sofrimento, enfim, a um atributo feminino ligado ao exercício sexual apenas, e não ao papel feminino.

Porém, para visualizar essa postura reducionista, é preciso que se recorra a informações acumuladas durante a formação médica, naquilo que se convencionou chamar de currículo oculto - os conhecimentos que não se encontram nos compêndios médicos. Estes são repassados, de maneira informal, às vezes ao longo das atividades próprias do curso, ou se desenvolvem em paralelo, mas influenciam fortemente os profissionais, inclusive na perpetuação de preconceitos e estereótipos.

Após a Segunda Guerra Mundial, a medicina passou por um processo de incorporação crescente de tecnologia para diagnóstico e tratamento das doenças que começaram, então, a parecer perfeitamente curáveis. A psiquiatria tradicional ganhou, na década de 50, potentes aliados: os benzodiazepínicos, drogas de amplo uso como calmantes, e a psicanálise, propondo fazer emergir os conteúdos reprimidos do inconsciente. 
Esses recursos pareciam capazes de manter sob controle manifestações antes indomadas, como a histeria. Novamente, chegou-se a propalar o seu desaparecimento. ${ }^{3}$ Porém, o que se observa é que esse diagnóstico perdurou no setor popular sob o rótulo de sofrimento dos nervos, ao passo que a medicina inventou um sucedâneo muito mais abrangente: o estresse. E, mais recentemente, tem jogado com os diagnósticos de depressão, TPM e com a atualíssima síndrome do pânico, na ânsia de justificar os incontáveis dependentes químicos que criou. Bulimia e anorexia também aparecem no rol de seus substitutivos e em estreita relação com a condição feminina.

\section{Estresse}

O homem é o único ser vivo capaz de ser seu próprio agente agressor; através de seus pensamentos, angústias $e$ inseguranças diante da vida (...) muitas pessoas experimentam sensações físicas de desconforto quando submetidas a situações de ansiedade.

Bonamim

Ao trazer aqui umas notas sobre o estresse, corri duplo risco: o de estender excessivamente essa revoada sobre a construção dos conceitos médicos sobrepostos à síndrome popular de nervos; e o de ser parcimoniosa na abordagem de tema tão discutido na imprensa médica.

Só fiz isso com o estresse, não o fazendo com a TPM e com a síndrome do pânico, ou com algum dos outros termos com os quais o quadro pode ser rotulado clinicamente, por entender que os mecanismos envolvidos na reação ao agente estressor explicam, de fato, o que se passa no nível orgânico com as nervosas. Como o que proponho neste trabalho é justamente promover uma interação cooperativa entre a biomedicina e a antropologia, deduzi serem os comentários ora expostos de grande utilidade.

Além disso, o estresse tem sido tema corriqueiro de matérias na imprensa leiga (jornais, programas de televisão etc.) e servido de justificativa para inúmeras situações, como se viu há pouco tempo, com a derrota da seleção brasileira de futebol na Copa do Mundo, atribuída ao estresse de um jogador. E mais: pelas descrições veiculadas, quer me parecer que o mesmo teve uma crise típica de nervos, mas como é homem, jogador de futebol, esperança da nação..., diz-se que ele teve estresse!

Os efeitos das condições da organização social e da sua desintegração sobre o comportamento e a formação da personalidade da pessoa foram assinalados já nos primórdios da sociologia, no final do século passado, por Durkheim. Na biologia, Hans Selye, médico e cientista austríaco, publicou, em 1936, suas primeiras observações sobre o estresse, e desde então muito se falou e se publicou na imprensa científica sobre o assunto. 
O próprio Selye (citado por Helman), em revisão publicada em 1976, mostrava que, em 40 anos, haviam sido publicados 110.000 estudos sobre o estresse. E, agora, o assunto talvez esteja mais do que nunca fazendo parte das conversas corriqueiras das pessoas, face à secularização e à vulgarização intensa do seu conceito (Feminina, 199?; Treichler et al., 1986; Stringueto \& Caruso, 1999).

O processo de vulgarização também atingiu, de certa forma, as áreas científica e profissional, a ponto de provocar indignação, como manifestou um psicanalista: "neste caso [na possibilidade de estabelecer-se um vínculo entre um acontecimento e a resposta somática], atualmente os biólogos falam com freqüência de stress, conceito saco sem fundo, de uso prático". (Dejours, 1988a:16) (grifo meu)

Esse uso do conceito de estresse como saco sem fundo, ou seja, como amplo reservatório no qual se jogam todas as coisas cuja causa é ignorada ou se pretende ignorar, é muito visto na área médica, principalmente. Mas implica um alargamento conceitual, pois passa a comportar situações muito diversificadas em sua natureza e gravidade. O termo é usado para qualificar tanto as ansiedades geradas por motivos de menor importância, no relacionamento pessoal com amigos, por exemplo, quanto as mais sérias, como as provocadas pelo trauma cirúrgico. Seu uso pode aparecer indiscriminadamente em situações corriqueiras como, por exemplo, "você está estressada porque eu mandei que fizesse dieta" e para designar a angústia que sucede a grandes tragédias, como a do sujeito que acaba de perder mulher e filhas carbonizadas num acidente automobilístico.

Mas, então, o que é o estresse? Nos termos propostos por Selye, constitui um mecanismo fisiológico que prepara o organismo para reagir às exigências ambientais. Decorre daí a compreensão de que nem todo estresse é deletério e indesejável. Num nível moderado (estresse), promoveria a proteção e a adaptação do indivíduo ao ambiente. Só em níveis mais acentuados (distresse) pode causar lesões patológicas, orgânicas ou psíquicas, e até mesmo levar à morte.

Os fatores estressantes podem ser de natureza física, psicológica ou sociocultural, e sua atuação provoca no organismo uma resposta manifesta em três estágios básicos:

- Alarme, em que há a conscientização da presença do agente estressante e a mobilização química, física e psicológica para enfrentá-lo.

- Resistência ou adaptação, com a ativação do sistema neuroendócrino e a conseqüente reação e recuperação orgânica.

- Exaustão, quando o organismo não é capaz de se recuperar, porque a persistência ou intensidade do agente estressante está além da sua capacidade de recuperação.

Assim, as mudanças fisiológicas se tornam patológicas, resultando, por fim, em doença ou morte.

Dada a natureza ambígua deste trabalho, pareceu-me imprescindível apresentar os mecanismos neuroendócrinos envolvidos na chamada Síndrome Geral de Adaptação, que é a reação aos agentes estressantes. Faço-o no Anexo 8, utilizando o excelente e descomplicado resumo encontrado em Witkin-Lanoil (1985a). 
É interessante ressaltar que os mecanismos de reação são inespecíficos, isto é, a forma como são ativados não tem a ver com a natureza do estressor, o que, por vezes, pode levar a uma reação desmedida em relação ao risco que este efetivamente implica.

Imagine-se, agora, uma situação estressante contemporânea: ficar preso no trânsito ou ter de enfrentar uma cirurgia (tanto no papel do cirurgião quanto no do paciente). Como ficam os sistemas todos ativados? Como sua ativação vai repercutir sobre o indivíduo que não pode ou não deve correr ou fugir? Certamente, intensificando aquelas respostas e desencadeando outras. Não fica difícil, portanto, imaginar o resultado das situações cronicamente estressantes, como viver numa grande cidade hoje em dia, ou conviver com a carência continuada de recursos materiais, ou, ainda, com relações conflituosas e frustrantes.

Decorre daí, provavelmente, o deslocamento conceitual que parece ter havido: estresse deixa de ser entendido como uma reação normal e passa a designar um desequilíbrio, como se encontra em alguns autores, que falam de um estado de desequilíbrio da pessoa por uma disparidade entre a demanda ambiental e a capacidade pessoal de lutar. Assim, os eventos atuam como estressores quando excedem os recursos adaptativos da pessoa.

O estresse provoca efeitos psicofisiológicos diretos sobre a saúde, como, por exemplo, doenças imunológicas, alergias, mudanças no funcionamento hormonal. Pode levar ao enfraquecimento das condições pessoais e a um comportamento doentio (enfraquecimento dos hábitos para a saúde), ou influenciar o curso de uma doença preexistente, pela superposição de outros sintomas (distúrbios do sono, anorexia etc.), retroalimentando-a e provocando o seu agravamento ou o surgimento de novas patologias ou comportamentos inadequados, como assinalam Maes, Vingerhoets \& Van Heck (1987).

Assim, estresse é hoje uma rubrica complexa, que consiste de processos interrelacionados, nos quais entram, além do sujeito, fatores mediadores entre os estressores ambientais e a doença, quais sejam, estilos de reação (repressão, inibição das expressões de emoção e engajamento com interações agitadas com o ambiente) e características de personalidade e das redes de apoio social.

O já citado Dejours fundamenta sua crítica ao uso indiscriminado do estresse na medicina, na psiquiatria e na psicologia, dizendo que usar o conceito de estresse

Evacua aparentemente a dificuldade em distinguir entre emoção e emotividade. ${ }^{+}$ (...) Libera-se também da distinção entre angústia somática e ansiedade psíquica. O stress se presta à objetivação, pouco importa a vivência do sujeito em estado de stress. (...) basta que se possam seguir as variações de grandeza biológica e que se possa lhes dar um índice de significação em relação com a situação ansiogênica estudada. (...) a mensuração do stress pode dispensar o sujeito que o vive. (...) Assim, o primado do mensurável se impõe em detrimento da vivência subjetiva, a ponto de torná-la acessória, até mesmo suspeita. Trágica orientação, pois do que falamos junto com o stress? De uma angústia supostamente isolável do sujeito que a vive. (Dejours, 1988b:26) (grifo meu) 
Como fato psicossocial, o estresse pode ser visto de várias perspectivas, tomando-se por base sua associação com papéis, estilos de vida, eventos da vida diária etc.

Entendendo nervos como uma das formas como algumas culturas, principalmente as latinas, enfrentam o estresse social, priorizei a abordagem dos papéis sociais, pois me interessavam, em particular, as questões de gênero e, nestas, as relacionadas às mulheres. Abordarei o tema mais adiante, no capítulo sobre gênero e nervos.

Goldberg (1992a), em interessante artigo sobre a problemática do atendimento ao estresse na Atenção Primária à Saúde (APS), reconheceu a existência de três grupos de distresse psicossocial: o primeiro, mais leve, no qual os mecanismos homeostáticos têm condições de promover sua recuperação após um certo tempo e que provavelmente não se benefíciará de medicação; ${ }^{5}$ o segundo, que seriam os neuróticos de longa duração, associados com problemas de interação social e problemas pessoais, cujo tratamento corresponde a uma intervenção social; e o terceiro grupo, o dos doentes, que se beneficiarão que se beneficiarão do tratamento comportamental e medicamentoso. Entendo que os sofredores de nervos possivelmente se concentrem no primeiro e no segundo casos; alguns talvez se encaixem no terceiro.

No mesmo artigo, Goldberg também discutiu as habilidades necessárias aos médicos para tratar desses pacientes, chamando a atenção para algumas que não podem ser adquiridas na escola médica: habilidade para o aconselhamento, para tolerar o paciente que não melhora, interesse continuado no ajustamento social e na melhora física do paciente e capacidade de perceber quando é necessário pedir ajuda social. Acentua que os jovens médicos, por não terem essas habilidades desenvolvidas, tendem a ajudar seus pacientes com a prescrição múltipla de fármacos e que isso não é bom, porque os pacientes gastam seu dinheiro com remédios em vez de fazê-lo com outras coisas, e porque as drogas, frequientemente, interagem deixando o paciente mais doente ainda. Além disso, incorrem em erro porque, de qualquer forma, é um engano primitivo do mundo a suposição de que problemas sociais crônicos possam ser resolvidos pelos psicotrópicos.

Outra questão freqüente, quando se fala de estresse e de nervos, é a da somatização, que, segundo Kleinman, é tanto a expressão de queixa física na ausência de patologia orgânica quanto a amplificação de sintomas resultantes de patologia física definida (Kleinman apud Dunk, 1989b).

O fenômeno da somatização, um dos componentes dos quadros de nervos, repercute sobre os serviços de saúde. Aqueles que tendem a expressar seu desconforto, pessoal ou social, no próprio corpo, vão encontrar má vontade e barreiras de preconceito e desconhecimento entre os profissionais de saúde, especialmente entre os médicos, tal como apontado por Goldberg e como será visto mais adiante.

Venho observando a força das representações acumuladas pela medicina, em sua longa história, cada vez que constato, por seus comentários e piadinhas a respeito de paciente, que os alunos da Universidade Federal do Paraná ainda recebem o mesmo tipo de orientação que recebi há mais de 20 anos. A única diferença está nos textos 
utilizados, que são muito mais compreensivos com a problemática socioafetiva e sugerem o trabalho médico baseado numa conceituação ampliada e que considere o processo saúde/doença. Porém, estes perdem sua força de convencimento diante do comportamento dos professores e profissionais mais experientes.

\section{Os Médicos e os Nervosos Hoje}

Nervos é uma doença popular com uma constelação sintomática que constitui uma síndrome socialmente reconhecida, à qual, como já foi visto, correspondem uma abordagem terapêutica e padrões de comportamento: tabus, regras de respeito ou de tolerância para com o doente etc. Mas, do ponto de vista biomédico, não existe como síndrome ou entidade nosológica, o que pode ser comprovado na consulta, por exemplo, a um dos livros-texto mais utilizados em nosso meio por estudantes e médicos, o famoso Cecil Textbook of Medicine, ou a algumas revistas médicas: mesmo as da área de psiquiatria nada trazem sobre nervos, apenas sobre histeria.

A síndrome popular do nervoso, compreendendo uma gama de sinais e sintomas emocionais e orgânicos, em associações e intensidade diversas, coincide, em geral, com a descrição clássica da histeria ou com o que os médicos reconhecem como piti ou psico. ${ }^{6}$ Engloba sintomas e sinais de natureza e de intensidade variáveis, não exclusivos. Muitos deles podem ser encontrados em doenças orgânicas, como algumas infectocontagiosas, ou nas consumptivas ou, ainda, nos estados depressivos.

É difícil precisar o sutil limite que faz com que um médico classifique um caso como depressão, por exemplo, ou - ao contrário - diga que não passa de um nervoso qualquer.

Em sua sintomatologia, o sofrimento dos nervos se assemelha muito com susto, que é uma doença de caráter cultural, encontrada entre os latinos. O susto, neste caso, se explica pelo roubo da alma do indivíduo (etiologia não verificada no presente estudo); também acontece em situações de conflito ou estresse social, parecendo incidir mais freqüentemente em mulheres e crianças (e. g. Seijas, 1972; Uzzel, 1974; O'Nell \& Rubel, 1980; Bolton, 198?; Trotter, 1982; O’Nell \& Selby, 1968a; Rubel, O’Nell \& Collado, 1995a; Holloway, 1994).

A exemplo dessa e de outras doenças culturais que também não são reconhecidas pela medicina oficial, o nervoso não tem uma abordagem específica. Pelo contrário, a consulta médica o despoja de seus significados e conteúdos sociais e o tratamento, dar um remedinho, ${ }^{7}$ raramente provê o doente de outros signos socialmente valorizáveis.

A consulta médica - exceto pela pequeníssima parcela que recebe uma prescrição medicamentosa - esvazia, desmerece o sofrimento do doente: isso é só um nervoso (cf. Navarro, 1989). Como consequiência, há a redução do contexto pessoal, ou seja, o 
impedimento de associações extra-biológicas intervenientes na determinação da doença que, afinal, promove a falta de articulação entre o nível biológico e o macro das determinações sociais da doença (cf. Verani, 1994).

Compartilho com Duarte (1987b) e Costa (1987c) a idéia de que os usos, popular e médico, do diagnóstico e do rótulo de nervoso constituem uma apropriação recíproca de saberes. Por um lado, o setor popular, localizando no corpo, ou seja, nos nervos, um distúrbio mal definido, tenta adequar-se à abordagem mecanicista da biomedicina e proporcionar uma rubrica admissível para uma categoria popular de doença. Por outro, o médico lança mão de um termo de uso popular (que já foi de uso médico, como se verá mais adiante) para definir, explicar, ou até mesmo se livrar da necessidade de fazê-lo, estados que envolvem situações tidas como clinicamente vagas, de múltiplos significados, quase sempre tomadas como idiopáticas ("o sujeito é assim mesmo, nada há a fazer..."), os quais, com um pouco mais de boa vontade, seriam chamados de psicossomáticos, mas que, principalmente, não merecem do profissional maiores preocupações além de um remedinho calmante ou para dormir.

Verhaak \& Tuhis (1992), assim como Goldberg (1992b), apontaram as dificuldades que os médicos clínicos gerais têm para diagnosticar os casos de problemas mentais quando eles se apresentam só com queixas somáticas. Lolas (1985) mostra os vieses subjetivos dos médicos - experiência, conhecimento, afetos -, que são parte constitutiva do processo diagnóstico.

Scheper-Hughes ilustra bem o embaraço da biomedicina ao lidar com síndromes culturais ou com sintomas ressignificados pela cultura, pela dificuldade que a medicina tem de apreender o real significado deles. Analisando o nervoso no Nordeste brasileiro, a autora percebeu que, na verdade, quando as pessoas se referem aos nervos estão, quase sempre, se referindo à fome ou às suas decorrências. O nervoso lá é o duplo da fome, ao passo que a leitura biomédica o vê apenas nos seus aspectos somáticos, desconsiderando a causa real do sofrimento e servindo como um agente de controle social. Como parte da prática discursiva, o a categoria nervos ameniza o peso político dos sintomas da fome, que exigiria a redistribuição de comida, riqueza e poder. Tratar o sofrimento como ansiedade emocional, patologia individual, e prescrever terapia tranqüilizante servem ao ocultamento da miséria, patologia social. Assim,

um rico esquema conceitual folk para descrever as relações mente/corpo/corpo social é apropriado pela medicina e transformado completamente em outro: a doença biomédica, que aliena a mente do corpo e oculta a relação social da doença. Assim, a experiência de privações é transformada em um problema pessoal, psicológico, que requer medicação. (Scheper-Hughes, 1992b:169)

No seu entendimento, a atuação dos médicos pode ser vista, à luz das teorias críticas e do conceito de hegemonia de Gramsci, como o desempenho do papel de intelectuais tradicionais, cuja função é, em parte, identificar mal, falhar em ver a secreta indignação da doença da pobreza expressa no pouco desenvolvido idioma dos nervos. 
A autora atribui ainda à medicina a tendência etnocêntrica de estandardizar nossas próprias táticas mente/corpo (culturalmente construídas e prescritas) e rotular como desviantes, patológicas, irracionais ou inadequadas as táticas dos outros (no caso estudado por ela, dos pobres) (Scheper-Hughes, 1992c:185).

A baixa resolubilidade da consulta médica é agravada também por outros fatores, como, por exemplo, o autodiagnóstico (atribuição pessoal ou social do rótulo de nervoso). Na consulta médica, que é um espaço, por definição, antipático ao autodiagnóstico e à automedicação, comuns nos nervosos, frases como "se sabe o que tem e/ou o que tomar, por que veio consultar?" ou "o médico [aquele que sabe, que está autorizado a falar de doenças] aqui sou eu!" são o revide corriqueiro de médicos impacientes.

Como uma categoria estranha ao médico, o nervoso pode até compor uma constelação sintomática, mas não tem o substrato etiopatogênico que dá consistência ao ato médico. Causalidade (social, emocional), sinais, sintomas, tudo é muito fluido, muito comum a vários estados para compor, por si, um conjunto convincente que, para o médico, mereça preocupação particular. Costa assinala ainda que: "Da Medicina o indivíduo reproduz as próprias incertezas do conhecimento psiquiátrico sobre a natureza da doença mental" (Costa, 1987d:14) (grifo meu).

E mais: para a biomedicina, existe uma oposição entre nervoso e realmente doente que desvaloriza muito o doente e sua experiência de sofrimento, bem como desconsidera o que ele está querendo expressar por meio de sua dor:

A gente sente tanta dor, se é real ou se é a cabeça da gente que inventa, eu não sei, mas não interessa, né? O que interessa é que a gente sente mesmo e chega no médico eles até tiram sarro da gente, ficam perguntando: "é o dedinho do pé que dói? Por que não diz logo que o dedão também está doendo?" Isso é sério, né? Se é a cabeça que faz, não sei, mas que a gente sente, sente dor mesmo, e os médicos não acreditam. (Paciente)

Só que às vezes eles [os médicos] pensam que é brincadeira ou que é uma mentira minha (...) eles ficam dizendo que é besteira, que é só do estado dos nervos. (Paciente)

Apesar de sua baixa resolubilidade, no entanto, a consulta médica é um buscada. Algumas razões podem ser apontadas para tal: primeiro, a consulta constitui um cenário ideal para uma narrativa de "queixas", monólogo no qual se afirma a identidade e o papel do queixoso e da própria queixa; segundo, tem a capacidade de legitimar socialmente o papel do nervoso como um doente, em seu meio (cf. Lock, 1991c); terceiro, detém a capacidade de dar resolução pragmática para alguns sintomas: o remédio para dormir, para a dor de estômago, o calmante etc.

A validade da doença é confirmada pela procura de suporte de médicos, familiares e amigos; pela prescrição de remédio para os nervos e shooks e pela hospitalização pelos nervos. (Schaik, 1989b:22) (grifos do autor) 
Buchillet (1991) e Rubel, O' Nell \& Collado (1990), entre outros, também assinalaram as mesmas conveniências da consulta para situações até certo ponto comparáveis à dos nervos, como no caso do susto, descrito por esse último autor.

As próprias pacientes o dizem:

Eu já penei de dor, de fraqueza, de nervo, de um tudo, já. Quando eu vinha da maternidade com dor, com ponto, fazia tudo sozinha, eu não fazia nem um luxinho. (...) ainda hoje passo incômodo, é muita coisa. Então, nem adianta contar que é muita coisa, nem vou conseguir contar direito. E outra: se eu contar isso para os médicos, o que eles vão dizer para mim? O que que eles vão fazer com isso? Só vou no médico para pegar a receita, né? O que vai adiantar contar para eles? (Paciente)

A biomedicina, que também se constitui em uma representação social construída por meio de categorias cognitivas, biologicamente embasadas, cujos conteúdos ideológicos têm implicações no reconhecimento e tratamento das doenças, adota e valoriza o estresse, mesmo o que se poderia qualificar como social, nas camadas médias e altas da sociedade. No entanto, tem dificuldades em lidar com o nervoso - que, embora seja seu equivalente para as camadas populares, é adotado na consulta apenas como um facilitador, mas não valorizado naquilo que significa - e a sua abordagem clínica se reduz à eventual prescrição de algum calmante ou sonífero. Quer dizer, seu tratamento é confinado à esfera biológica, mesmo que sua causalidade se localize no âmbito emocional e social.

Nesse jogo de construções, as populares, por um lado, e as médicas, por outro, aprisiona-se o sofredor nas armadilhas do diagnóstico biomédico, determinando o que Chiozza define como a dependência do doente somático às instituições e estruturas da assistência médica. Estas despojam de sentido a sintomatologia exposta, encurralando o paciente no espaço mais estreito definido pela subcultura médica (Chiozza, 1987c). ${ }^{8}$ Entendimento mais dinâmico desse processo é encontrado em Alves (1994b), que afirma que o processo dialógico com agentes terapêuticos e outros significativos de sua comunidade possibilita ao sujeito a criação ininterrupta de explicações para a doença. Para ele, modelos interpretativos desenvolvidos são essencialmente processuais, pois resultam dos constantes contatos e das discussões mantidas ao longo da enfermidade.

Essa estreita vinculação do diagnóstico às estruturas contidas num modelo teórico preso a formulações mecanicistas, biologicistas, e que mantêm a dicotomia corpo/mente, explica por que, mesmo na sua versão mais aberta à problemática social, que é a epidemiologia, a biomedicina pouco esclarece sobre o sofrimento, sobre a singularidade e a estranheza do fato de sentir-se doente. E esclarece menos ainda sobre as incontáveis possibilidades culturais de compreensão dos fenômenos ligados à saúde e à doença, sobretudo no campo simbólico, em que se inserem as possibilidades de leitura dos significados sociais que podem ser reveladores das relações sociais sobre as quais elas se formam e que, ao mesmo tempo, refletem. 
Entre as consequiências da postura médica, duas das mais graves são, sem dúvida, a medicalização excessiva e o uso abusivo de medicamentos psicoativos, como os calmantes e hipnóticos, o que não se faz sem graves riscos pessoais e sociais (e. g. Malavolta, 1994a; Lima \& Esmeraldino, 1995a). Adiante, discutirei essa problemática mais amplamente.

A ida ao médico serve ainda como uma forma de sair da crise, de resgatar a dignidade pessoal, principalmente quando aquela se deu por manifestações muito extravagantes em relação ao comportamento habitual:

Quando me dá o ataque dos nervos, fico tão louca que nem sei o que faço. Até rasgar a roupa lá no posto de saúde eu já rasguei uma vez; aí eu fico com muita vergonha, então eu vou no médico que é pras vizinha, pros parentes dele [do marido] verem que eu faço isso por doença mesmo, que não é por falta de vergonha. (Paciente)

Uma vez me deu uma crise no baile, dizem que fiz o maior escândalo, eu nem me lembro direito, dai eu melhorei e o pessoal em volta dizendo que era pra ir no hospital. Eu já estava boa, mas fui só de vergonha, daí me deram um calmante e eu voltei pra casa dormindo, só saí de casa dali uns três dias. Se eu não tivesse ido e tomado a injeção, não tinha cara de enfrentar as pessoas, mas daí, como o médico me deu até injeção, ninguém ficou falando, senão já viu como ia ser o falatório do povo, não iam acreditar que eu fiz sem querer. (Paciente)

Às vezes eu acho que ela vai no médico só pra não passar vergonha depois do que fez quando estava atacada. (Informante, sobre uma paciente)

Quando eu vejo que me descontrolei demais, daí eu vou ao médico para não ficar muito chato, assim se ele me dá uma receita ou um atestado. Todo mundo se cala. (Paciente)

\section{Acalmando Médicos e Pacientes: a Receita aZul}

Eu não entendo, algumas vezes fui com a minha prima no médico; quer dizer, em mais de um... Aí eles falavam para ela bem assim: isso não é nada, é só dos nervos, da tua cabeça, é só querer que se controla, mas davam uma carrada de receita, tudo de remédio forte, receita azul, né? E diziam que ela não podia passar sem eles, agora acho até que ela já está assim que nem esses drogados, fica louca se tiver se acabando o remédio e ela não puder ir pegar mais receita. O médico às vezes dá receita azul como quem dá cheque: pré-datado!

(Informante)

Ao abordar a forma de como os médicos encaram e se posicionam diante de nervos, e sem abandonar, mesmo que temporariamente, o ponto de vista das pacientes, ${ }^{9}$ busquei no outro lado, na perspectiva médica do tratamento de nervos, alguns elementos que pudessem esclarecê-la melhor. Essa é uma problemática tão complexa, que merece não só uma dissertação à parte ${ }^{10}$ mas o concurso de outros profissionais 
(farmacêuticos, bioquímicos, semiólogos, especialistas em educação médica, entre outros) para uma abordagem mais acurada. Por essa razão, em vez de tentar a sua análise, preferi apontar aqui, para reflexão, alguns de seus aspectos mais marcantes.

O tratamento de histéricos e nervosos, como foi visto, acompanhou os modelos conceituais a ele subjacentes. Porém, atualmente persistem alguns comportamentos terapêuticos que não se explicam por essa via, e sim por outros componentes do imaginário médico e popular, os quais estão, ao que parece, muito ligados a preconceitos de gênero e a conteúdos simbólicos ligados aos medicamentos.

Ao longo da história, recomendaram-se abstinência, moderação ou ênfase na atividade sexual, inalações de odores desagradáveis e uso de pessários perfumados. Em dado momento foram indicados banhos, contra-indicados em outros. Até leituras entraram nesse rol, ora aprovadas, ora desaprovadas, pois em um momento eram tidas como terapêuticas, em outros como etiologia do mal que propunham tratar!

Algumas medidas continuariam até nossos dias, recomendadas textualmente ou não. Umas, milenares até, mostraram enorme persistência, tanto nas escolas médicas quanto no setor popular: embora seu modelo explicativo tenha caído em desuso há centenas de anos, ainda se mantêm, como é o caso da inalação de sal amoníaco ou da noz-moscada. Outras, mais agressivas, pouco admitidas, se empregam ainda hoje em serviços de pronto atendimento, como o famoso tapa na cara ou a injeção de água destilada ou de éter," ambos tidos como de grande eficácia por médicos e outros profissionais, para acabar com o fingimento de pacientes histéricos. Na verdade, em minha vida, tanto como estudante de medicina quanto como profissional, não tive notícia de paciente do sexo masculino, histérico, haver recebido tapa na cara. Para mulheres, entretanto, eu mesma presenciei esse tipo de tratamento!

A década de 50 trouxe uma novidade terapêutica de enorme repercussão: os benzodiazepínicos, então introduzidos na prática médica psiquiátrica. Trata-se de medicamentos tranqüilizantes, de ação psicotrópica e efeitos sedativos, que provocaram o desenvolvimento de uma disciplina específica, a psicofarmacologia ${ }^{12}$ e que hoje têm uso amplo e muitas vezes abusivo.

O controle não só das histéricas mas dos pacientes psiquiátricos em geral ganhou reforço com esse método químico de contenção. Para Szasz, seu uso confirma "a crença de que as perturbações psiquiátricas são doenças médicas, curáveis com medicamentos específicos" (Szasz, 1971:359).

Sua descoberta trouxe benefícios indiscutíveis para os pacientes e facilidades para os médicos, ${ }^{13}$ porém provocaram uma iatrogenia específica, desencadeada, principalmente, pelo mau uso desse recurso terapêutico.

Esse grupo de drogas, embora não tendo banido definitivamente antigas práticas terapêuticas, tomou um assento definitivo junto a médicos e pacientes, como atesta a substância chamada diazepam (a mais conhecida representante dos diazepínicos), usada diariamente por muitos milhares de brasileiros de todas as camadas sociais. No 
Brasil, existem pelo menos 228 produtos comerciais contendo benzodiazepínicos ou assemelhados. Drogas desse grupo, como o Valium®, o Lorax ${ }^{\circledR}$, o Dienpax ${ }^{\circledR}$ etc. são bem conhecidas, tanto entre os médicos quanto entre leigos, e largamente utilizadas.

Não bastasse essa abundância, ainda:

Há uma propaganda indiscriminada desses produtos (...). Um exemplo dessa difusão, em revista médica, apresenta uma propaganda cínica: uma moça bonita seminua, numa cama de casal em que o outro lado está propositalmente vazio (...). Após o uso do benzodiazepínico ela dorme muito bem (...). Estava angustiada, tensa, sentindo a falta de alguém (...). Então tomou o remédio e clormiu, não precisa mais da companhia que lhe fazia falta. (Carlini, 1995a:86) (grifo meu).

Portanto, não é de se estranhar que consultar um médico por problema de nervos pareça resultar quase sempre numa receita azul, conforme informaram as pacientes entrevistadas. Sua informação coincide também com o que se ouve mesmo de médicos:

Os caras por aí [os outros médicos] enchem esses pacientes [sofredores de nervos]

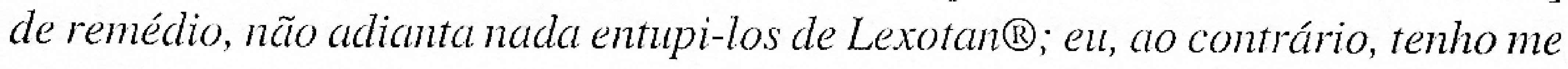
saúdo bem com um maracujá, uma melissa, qualquer desses chazinhos resolve esses casos; até Maracujina@ ${ }^{14}$ tenho dado para isso e dá certo. (Médico, ilhéu)

Aquela mulher volta e meia liga no meio da noite e quer que eu vá ao consultório atendê-la... Era só o que me faltava! O jeito, para ela sossegar, é não deixar a receita azul faltar. Se ela aparece no posto de saide, dou logo receita para uns dois meses. (Ouvido por acaso, de um médico, a propósito de uma paciente de nervos)

Barros (1995) informa que os tranqüilizantes estão em quarto lugar em volume de vendas no Brasil, o que, se confrontado com as principais causas de adoecimento e morte, ${ }^{15}$ evidencia o exagero com que são prescritos. Distorções no uso devem-se tanto a indicações quanto a doses imprecisas ou inadequadas e, principalmente, à duração do tratamento.

Essa situação não é nova. Uma das denúncias mais veementes é encontrada em Ilich: "Nessa situação de invasão farmacêutica, não é de surpreender que os tranqüilizantes sejam o tipo de arma que se amplia mais rapidamente" (Ilich, 197?a:52).

E a conseqüência previsível desse exagero impõe, segundo ele, um duplo roteiro para o médico:

Cada vez mais o médico se vê em face de duas categorias de toxicômanos: à primeira ele prescreve drogas que criam hábito; à segunda dispensa cuidados para tratar de pessoas que se intoxicam por conta própria. (Ilich,197?b:56)

Nesta pesquisa, os achados coincidem com o que os outros pesquisadores têm mostrado: medicalização de problemas socioafetivos, econômicos e outros não passíveis de melhora com calmantes, erros na dosagem e uso prolongado de agentes psicoativos, com graus de dependência e iatrogênese variáveis (Gudex, 1991; Malavolta, 1994b; Rozemberg, 1994b; Lima \& Esmeraldino, 1995b). 
Mesmo o proprietário de uma farmácia pública no Campeche acha exageradas as receitas que recebe:

Essa [paciente] tinha um tempo que vinha demais aqui, não sei onde ela conseguia tanta receita azul, até nós falávamos para ela que assim [tomando muitos calmantes] iria se viciar, agora faz tempo que ela não vem...

O que mais sai aqui é Lexotan (B, antes era o Diazepam (B... Lexotan (B é o da moda agora...

Algumas vezes, aquela outra paciente já veio com mais de uma receita no mesmo mês.

Além do poder simbólico de representar a saúde (Lefèvre, 1991a), o medicamento carrega outras propriedades semióticas: as pacientes, de maneira geral, negam o uso exagerado de calmantes, mas tal posse lhes confere uma espécie de autoridade e de poder, já que substâncias fortes, como elas mesmas reconhecem, passam a ser de sua competência, e tanto podem recorrer ao medicamento como bem lhes aprouver quanto podem socorrer pessoas em situações semelhantes às suas, ou, ainda, manipular o grupo familiar ou o de vizinhança, estabelecendo uma verdadeira rede de tráfico de medicamentos:

Tenho um vizinho que, quando falta o remédio para ele, eu empresto, senão ele fica louco e quer se matar, ele já esteve até na Colônia. Para ele eu empresto sim, que ele já toma há 25 anos! Só que às vezes o médico dele não quer dar a receita ou está viajando, aí ell empresto, depois ele pega as receitas dele e me traz de volta. Se eut não faço isso, ele pode até se matar.

A médica já disse que estou dependente, também nove ano [tomando calmantes], né? Só tinha que viciar. Quando vou ficando só com uma caixa, vou enlouquecendo de medo de acabá e eu não ter outra receita, mas também não sou igual àquela [a que tomou os comprimidos na frente dos médicos].

Eu sei que éforte, né? Mas por isso mesmo é que não gosto que falte em casa, se eu preciso. Ou, às vezes, eu posso ajudar uma pessoa que está passando por uns nervos, já que não tenho outro recurso mesmo. Posso valer com um remédio forte, bom para ela. (Paciente)

Ter a medicação em casa permite que a própria paciente faça a profilaxia das crises, das suas e das prováveis crises dos outros. Talvez para os profissionais essa seja uma atitude até mesmo desejável:

Eu gosto de ter bastante remédio em casa, assim eu vou tomando como eu acho que é preciso. Mas também gosto de servir os outros, se acontece assim, por exemplo, uma morte de alguém conhecido quando eu vou na guarda eu já levo um pouco do calmante, se precisarem, se tiver alguém muito nervoso, eu pego e dou uns comprimido. Se a gente que é doente não tiver um pouco de sobra nessas horas, fica difícil ajudar, né? (Paciente)

Às vezes, aqui em casa, eu digo: quem está nervoso são vocês! Aí eu pego do meu remédio e dou para as filhas, até o marido eu já fiz tomar uma vez para ele me dar sossego e não sair pro bar. (Paciente) 
Agora, se não tomo Diazepam, não posso ouvir uma notícia ruim, uma doença, uma morte de alguém, seja quem for, já me dá a crise. (Paciente)

Tem uma médica num posto de saúde que já me dá receita azul para uns meses. Ela diz: assim a senhora me dá um pouco de sossego! Mas não é só ela não, tem muito médico aí que quer ver a gente pelas costas, se eu lhe contar a senhora vai se arrepiar, que a senhora é médica também, pode não gostar da gente contar isso. (Paciente)

A maioria dos médicos não está nem aí se a pessoa vai ou não melhorar, se pode se matar com o remédio ou dar para um que não pode tomar aquilo, eles dão receita para muito remédio que é para a pessoa que sofre de nervos ficar bastante tempo sem voltar. Também, coitados! Eles também cansam de tanto atender gente com nervos! (Informante)

Entre as entrevistadas, apenas duas pacientes demonstraram ter algum conhecimento sobre os efeitos colaterais e a necessidade de prudência em seu uso, até mesmo recusando-os, como contou uma delas:

Eu tinha um barulho no ouvido, tomava calmante por causa disso, mas não gostava de calmante, me deixava ruim; depois um psicólogo me ensinou controlar com a respiração e uns chá, de chá eu gosto, do cheirinho de mato, de alecrim, de cidreira, dá uma sensação de paz, um macumbeiro que eu fui uma vez também mandou tomar chá; sei lá, de chá eu gosto, acho que faz bem e não tem perigo que nem calmante, de viciar ou fazer mal, não sei...

Algumas pacientes contam que no início de seus tratamentos tinham medo de "remédio controlado, porque eles são fortes", mas que os próprios médicos e alguns balconistas de farmácia lhes garantiram tratar-se de "remédios bons; bom para ter em casa, que não viciam, nem fazem mal, só acalmam ou ajudam a dormir". Porém, uma autoridade em farmacologia diz o contrário:

A abstinência aos benzodiazepínicos, principalmente aqueles de curta e média ação (triazolam, midazolam, lorazepam, etc.), tem sido cada vez mais descrita na literatura. Nos casos mais graves são observadas alucinações, convulsões generalizadas, e depressão geral da consciência. Entretanto, são muitos os casos de descrições de síndromes e abstinência após a retirada de benzodiazepínicos de ação longa, como o diazepam e o clordiazepóxido. (Carlini, 1995b:96) (grifo meu)

Atualmente, a título de profilaxia da dependência, a Organização Mundial da Saúde vem recomendando que a terapêutica com benzodiazepínicos não deve ultrapassar quatro semanas em qualquer circunstância. (Carlini, 1995c:96) (grifo meu)

A abordagem terapêtica evidencia uma grosseira incongruência entre o diagnóstico e o tratamento, pois ao mesmo tempo que o médico diz “isso não é nada!", não se dispondo a dar um pouco de atenção que seja à paciente, dá-lhe receitas azuis a mancheias, sem certeza alguma do uso que ela possa fazer da fartura de psicotrópicos. 
Uma perspectiva que certamente pode contribuir para que se entenda melhor a complexidade da análise da prescrição médica é a apresentada por Lefèvre (1991b) em seu livro O Medicamento como Mercadoria Simbólica. Considerando-se, como ele propõe, que:

Portanto, não se nega - o que seria um absurdo - que o medicamento cura, controla e previne (dimensão quimioterápica/médica); não se afirma simplesmente que aliena e domina (dimensão social e psicossocial) e que representa e simboliza (dimensão semiótica e simbólica). É pois dentro desta perspectiva mais ampla que buscamos entender o objeto medicamento, localizando-o em regiões mais críticas do tecido social das formações sociais capitalistas como a brasileira, o que implica entendê-lo como uma mercadoria, que traduz um processo de reificação da saúde; como um agente quimioterápico, que funciona aliviando, curando e controlando processos mórbidos do organismo e como símbolo que permite que a saúde (ou, mais precisamente, a saúde "biologizada") esteja representada no medicamento. (Lefèvre, 1991c:19) (grifo meu)

Buscando-se razões para uma prescrição aparentemente excessiva de calmantes, dentro do espaço de explanação proposto por esse autor, poder-se-ia levar em conta que, para o médico, o medicamento, além de, obviamente, simbolizar a saúde ou a cura, simboliza a própria relação terapêutica, e a mantém mesmo diante de sua insegurança. Reproduz, ainda para o médico, o poder que o medicamento tem para o paciente, na medida em que é ele quem o prescreve e, por meio da sua prescrição, administra esse poder (Lefèvre, 1991d).

A situação mais grave quanto à prescrição medicamentosa encontrada na presente pesquisa diz respeito à forma de como o serviço público de saúde de Florianópolis, para tentar coibir o seu abuso, organizou a distribuição de receitas azuis: os pacientes de nervos eram, à época da pesquisa, encaminhados a um psiquiatra da rede pública uma vez por semestre. O psiquiatra, após uma consulta rápida, ${ }^{16}$ avaliava o problema e fornecia uma autorização para a prescrição de psicotrópicos, válida por seis meses, que lhes permitia pegar receita uma vez por mês e, eventualmente, o medicamento também (gratuito), em qualquer centro de saúde do município, independentemente de serem examinados por um médico. A prática comum, segundo a pesquisa, era a de a paciente, estando de posse de uma autorização, percorrer vários postos da ilha, e mesmo do continente, em busca de receitas, e colecionar em casa remédios ou receitas prontas para serem aviadas. ${ }^{17}$

Porém, nervos carrega muito mais significados do que aqueles propostos para a histeria ou a própria concepção médica de nervos, calcada na negação - "isso não é nada" - ou no preconceito - "ela precisa é de homem!". E, ao romper os limites desse modelo explicativo biomédico, exige mais do que a abordagem medicamentosa e não aceita a negação que lhe é sistematicamente imposta nas consultas - "não é nada, é só nervos..." -, contrapondo-a freqüentemente à prática da prescrição:

Mas se eles [os médicos] dizem para a gente que nervos não é nada, que é só a gente se controlar, por que dão tanta receita de remédio azul? Por que eles não ensinam como fazer para se controlar? Parece que só querem se ver livres da
gente! (Paciente) 
Eu não fico sem meus remédios da receita azul, já viciei e a culpa foi dos médicos mesmo, eles vivem dizendo que isso que eu tenho não é doença, mas eles mesmos entopem a gente até se viciar. (Paciente)

Evidenciou-se que, ao menos da perspectiva das pacientes e de seus familiares, a medicalização de problemas sociais tem funcionado como solução para o médico, pois as pacientes, a despeito do uso de calmantes, continuam a ter crises. Voltam para a sociedade seu gume mais afiado, qual seja, o do agravamento do sofrimento dos nervos com a adição medicamentosa, criando cada vez mais viciados em drogas legais, iatrogenicamente cevados pelos seus médicos, o que nos remete ao comentário, já mencionado, de Ilich. E a trabalhos mais recentes, como o de Vargas, que coloca em pauta a responsabilidade médica na drogadição com drogas legais, ou seja, na criação de novos drogaditos a partir da prescrição das drogas ditas lícitas, medicamentos que criam hábito e por isso viciam os seus usuários. O autor afirma, inclusive, crer que "jamais se incitou tanto ao consumo de entorpecentes, nunca seu uso foi tão prescrito e estimulado como nos tempos atuais" (Vargas, 1999:122) (grifo meu).

Deixando a questão terapêutica dos nervos ainda aberta para reflexão e discussão futuras, consigno aqui a opinião de um médico que atua na ilha (aquele que se mostrou sensível à problemática dos nervos) sobre o uso de benzodiazepínicos, também qualificado por ele como abusivo:

\begin{abstract}
Os médicos que dão benzodiazepínicos represam o rio ou querem que ele corra contra seu curso natural, por isso o tratamento não é eficaz. Já as benzedeiras deixam o rio correr livremente e sua atenção émelhor, nesses casos. Os diazepínicos propiciam uma passagem da vida cotidiana, problemática, para um local imaginário no qual ela pode viajar e se sentir bem. ${ }^{18}$ O diazepinico para a mulher e o álcool ou outras drogas para o homem é a vagina, a passagem que propicia o nascimento, a passagem para o imaginário, para esse lugar sem problemas, o gargalo do funil. A benzedeira não faz isso, ela deixa o rio fluir e a situação que gerou o nervoso se resolver, porque, com o remédio, ela persiste, e, quando falta, a paciente é trazida de volta, abruptamente, para o mundo real, onde estão os seus problemas, à espera de serem resolvidos, e começa tudo de novo...
\end{abstract}

\title{
NoTas
}

1 Deve-se levar em conta que o modelo biomédico que caracteriza o modelo oficial de assistência médica vigente no país é baseado no modelo flexneriano, no qual os fundamentos cartesianos são acentuados, conferindo-lhe, além da postura mecanicista e biológica, um caráter individualista. Decorre daí sua organização em especialidades cada vez mais fragmentadas e fragmentadoras e sua preocupação com a cura. É o que se chama em saúde pública de modelo assistencial flexneriano de inspiração positivista. 
2 Seria desejável que o fizesse de fontes primárias, porém, dificuldades de várias ordens, entre as quais a impossibilidade momentânea de a elas ter acesso, levaramme a uma revisão histórica parcial, baseada em alguns autores, e. g. Foucault (1993), Israël (1995), Porter (1993), Szasz (1971), Trillat (1991) e Veith (1973), que se têm ocupado da histeria e da loucura.

3 No meio médico, vez ou outra isso ainda é considerado.

4 Para ele, a emoção atua mais no nível visceral, na musculatura (motricidade digestiva), na motricidade vascular (vasoconstrição, vasodilatação, taquicardia, hipertensão arterial), motricidade respiratória (taquipnéia diafragmática ou intercostal, espasmo brônquico); lágrimas, riso, animia também fazem parte das manifestações de emoção. A emotividade, por sua vez, se distingue da emoção: indica o modo particular de reagir, manifestações privilegiadas de certos indivíduos diante de situações exteriores e de excitações (cf. Dejours, 1988).

5 Acrescento: é quase certo que esse grupo não precisará da medicação, a não ser, em raros casos, por curtíssimo período de tempo.

- Piti, de pitiático, histérico, que tem sintomas que aparecem pela sugestão e desaparecem pela persuasão (cf. Ferreira, 1960); psi, radical que se refere a alma, espírito, aqui usado pejorativamente para indicar os que nada têm de sofrimento organicamente localizável.

7 Enfatizo a expressão por ser muito usada pelos médicos para se dirigir aos pacientes. A meu ver, essa forma, mais apropriada às crianças, faz parte de um processo de desvalorização do paciente, não só de suas queixas, mas também de seu conhecimento.

8 Utilizo o termo subcultura médica sem outras conotações conceituais, querendo apenas aproveitar da praticidade da expressão para me referir a aspectos restritos da cultura, próprios de um segmento da sociedade, no caso o profissional biomédico.

9 Ponto de vista é, como diz Lefèvre (1991), o ponto no espaço, no caso, sociocultural, de onde alguém vê o mundo e que condiciona, determina, limita o que ele vê.

10 As referências sobre psicotrópicos ou sobre tratamentos psiquiátricos, psicológicos e psicanalíticos nas bases de dados bibliográficos de qualquer biblioteca da área de saúde são quase inesgotáveis, o que torna a revisão bibliográfica uma tarefa hercúlea.

11 Em 1997, o jornal Folha do Paraná publicou a história de uma mãe que, em Foz do Iguaçu, PR, num serviço público de saúde, recebeu uma injeção de éter (muito dolorosa) na região tibial, dada, segundo ela, pelo médico, para acalmá-la; ela estaria, segundo ele, muito nervosa. Ela, ao contrário, afirmava que só estava preocupada com o estado de saúde de seu filho. No local da injeção houve necrose e este era o motivo da denúncia que ela fazia, pois estava sujeita, em decorrência dessa lesão, a ter de fazer um enxerto (França, 1997). 
12 Carlini (1995) assinala que o uso desse termo é muito anterior ao surgimento desse grupo de medicamentos: em 1545, foi publicado um livro intitulado Psycopharmackom, de cunho teológico, que se propunha ensinar as pessoas a bem viver para bem. morrer.

13 Piadinha recorrente em serviços de pronto atendimento: o paciente ganhou uma receita de calmantes para que o médico pudesse dormir (e não ser incomodado por um piti).

14 A maioria dos médicos considera este produto não ético por ser de venda livre e fazer parte de um receituário popular, de automedicação, no sentido amplo do termo.

15 As principais causas de adoecimento e morte, no Brasil, são ainda as doenças infecciosas e o crescimento mais recente das doenças crônico-degenerativas, como pode ser verificado no Boletim Epidemiológico, publicação regular do Ministério da Saúde do Brasil.

16 Pacientes e familiares insistiam nisso, muitos dizendo terem registrado, observando o relógio, que as consultas não chegavam a 15 minutos de duração.

17 Ao final da pesquisa de campo ela foi apresentada, a pedido, para a equipe então atuante no Centro de Saúde do Campeche. Na reunião, evidenciou-se que os profissionais de saúde desconheciam as peculiaridades da obtenção, uso e manipulação das receitas de psicotrópicos pelas nervosas e demais pacientes. A informação causou grande preocupação entre eles e motivou que assumissem o compromisso de levar o fato ao conhecimento de seus supervisores, com a proposta de discutir uma forma de estabelecer um controle rigoroso do fornecimento de receitas azuis e de medicamentos controlados.

Irônico, acrescentou: onde há um homem de capa preta montado num fogão Brastemp® à espera dela. Aludia ao sonho do príncipe encantado e a um sonho de consumo das mulheres, fartamente alimentado pela mídia televisiva na época. 